\title{
Repellent and insecticidal efficacy of a new combination of fipronil and permethrin against the main vector of canine leishmaniosis in Europe (Phlebotomus perniciosus)
}

Pascal Dumont ${ }^{1}$, Becky Fankhauser ${ }^{1}$, Emilie Bouhsira ${ }^{2}$, Emmanuel Lienard ${ }^{2}$, Philippe Jacquiet $^{2}$, Frederic Beugnet ${ }^{1 *}$ and Michel Franc ${ }^{2}$

\begin{abstract}
Background: Two successive laboratory experiments (A and B) were conducted to confirm the efficacy of a new fipronil and permethrin combination to repel and kill Phlebotomus perniciosus sandflies when applied once topically on dogs.

Methods: Due to the difficulty to get enough available dogs and sandflies in one run, the study was divided into 2 experiments which had exactly the same design, and were conducted at the same place, with the same technicians. They compared dogs treated with a combination containing $67.6 \mathrm{mg} / \mathrm{mL}$ fipronil $+504.8 \mathrm{mg} / \mathrm{mL}$ permethrin (Frontect ${ }^{\oplus} /$ Frontline Tri-Act ${ }^{\oplus}$, Merial) to untreated dogs. The treatments were applied topically once on Day 0. Sandfly exposures were performed on Days 1, 7, 14, 21 and 29 with 80 P. perniciosus female sandflies. After $60 \mathrm{~min}$, sandflies were assessed for vitality and engorgement status. Live sandflies were kept in an insectary and observed for mortality counts $4 \mathrm{~h}$ after the exposure period ended.

Results: Percent sandfly repellency on treated dogs was 98.2, 98.5, 99.2, 90.9 and 90.3\%, for Days 1, 7, 14, 21, and 29 , respectively. There was a significant difference $(p \leq 0.05)$ between the treated and control groups in both experiments and for the pooled data on every assessment day.

Insecticidal efficacy on treated dogs at $4 \mathrm{~h}$ post-exposure on Days 1, 7, 14, 21 and 29 was 98.7, 99.7, 96.8, 93.4, and $78.9 \%$, respectively. There was a significant difference between the treated and control groups for live sandflies observed at $4 \mathrm{~h}$ post-exposure for all assessment days $(p<0.05)$.

Conclusions: A single topical administration of a new combination of fipronil and permethrin demonstrated a significant repellent effect (i.e., > 80\%) against P. perniciosus which lasted for 29 days after application. The repellent effect was accompanied by a significant insecticidal effect on sandflies. The results suggest that in endemic areas, the application of the fipronil-permethrin combination could be integrated into canine leishmaniosis prevention program.
\end{abstract}

Keywords: Repellent, Phlebotomus perniciosus, Sandflies, Fipronil, Permethrin

\footnotetext{
* Correspondence: frederic.beugnet@merial.com

1 Merial S.A.S., 29 Av Tony Garnier, 69007 Lyon, France

Full list of author information is available at the end of the article
} 


\begin{abstract}
Abrégé
Contexte: Deux études expérimentales successives (A et B) ont été conduites afin de confirmer l'efficacité d'une nouvelle combinaison de fipronil et de perméthrine pour repousser et tuer les phlébotomes Phlebotomus perniciosus après une application unique chez le chien.

Méthodes: En raison de la difficulté à disposer de suffisamment de chiens et de phlébotomes en une fois, l'étude a été divisée en deux expérimentations ayant le même protocole, conduites au même endroit, et par les mêmes opérateurs. Elles ont comparées des chiens traités avec une combinaison contenant du fipronil à $67,6 \mathrm{mg} / \mathrm{mL}+$ de la perméthrine à $504,8 \mathrm{mg} / \mathrm{mL}$ (Frontect ${ }^{\oplus} /$ Frontline Tri-Act ${ }^{\oplus}$, Merial) à des chiens non traités. Les traitements ont été appliqués en topique une fois au jour 0. Les expositions ont été réalisées aux jours 1, 7, 14, 21 et 29, avec 80 phlébotomes $P$. perniciosus femelles. Après 60 min, les phlébotomes ont été évalués pour leur vitalité et leur statut de gorgement. Les phlébotomes vivants ont été placés en insectarium et leur mortalité observée/comptabilisée $4 \mathrm{~h}$ après la fin de la période d'exposition.

Résultats: Le pourcentage d'activité répulsive observé chez les chiens traités vis-à-vis des phlébotomes a été de 98,2, 98,5 99,2 90,9 et 90,3\%, aux jours 1, 7, 14, 21 et 29, respectivement. A chaque jour d'évaluation, la différence était significative $(p \leq 0,05)$ entre les chiens traités et non traités, dans les deux expérimentations comme pour les données combinées.

Chez les chiens traités, l'efficacité insecticide 4 h post-exposition était de 98,7,99,7,96,8,93,4, et 78,9\% aux jours 1 , $7,14,21$ et 29. A chaque jour d'évaluation, la différence a été significative $(p<0,05)$ entre les groupes traité et non traité quant au nombre de phlébotomes vivants $4 \mathrm{~h}$ post-exposition.

Conclusions: Une seule administration topique de la nouvelle combinaison de fipronil et de perméthrine a démontré un effet répulsif significatif (i.e., > 80\%) contre P. perniciosus durant 29 jours après l'application. L'effet répulsif était accompagné d'une action insecticide significative sur les phlébotomes. Les résultats suggèrent qu'en zone d'enzootie, I'application de la combinaison fipronil-perméthrine pourrait être intégrée dans un programme de prévention de la leishmaniose canine.
\end{abstract}

\section{Background}

Leishmaniosis is a serious parasitic disease caused by flagellated protozoa of the genus Leishmania. The protozoa are transmitted to animals and humans by haematophagous female sandflies of the genus Phlebotomus in the Old World and Lutzomyia in the New World. Although certain wild mammals may be involved in the transmission of leishmaniosis, domestic dogs appear to be the principal reservoir of Leishmania infantum throughout the world [1]. In Europe, there is a tendency for leishmaniosis but also other canine vector-borne diseases to have an increased distribution [2]. This is related to several factors, including climate and social changes [3].

The prevention of canine leishmaniosis in dogs is based on several measures, including anti-Leishmania vaccines and methods for protecting healthy dogs against sandfly bites $[4,5]$. The studies reported here were conducted to assess the repellent and insecticidal efficacies of a new spot on topical combination of fipronil and permethrin (Frontect ${ }^{\circ} /$ Frontline Tri-Act ${ }^{\circ}$, Merial) against the main vector of canine leishmaniosis in Europe (Phlebotomus perniciosus). Such a combination is intended to provide both repellent and insecticidal-acaricidal effects against several ectoparasites of dogs $[6,7]$.

\section{Methods}

Two successive experiments were conducted at the Ecole Nationale Vétérinaire de Toulouse. The 2 experiments were necessary due to the difficulty to include many dogs and to produce enough sandfly. Experiment A was also considered as a preliminary exploratory study whereas Experiment $\mathrm{B}$ was conducted according to Good Clinical Practices (GCP) as described in the International Cooperation on Harmonisation of Technical Requirements for Registration of Veterinary Medicinal Products (VICH) guideline 9 [8].

\section{Animals}

Adult Beagle dogs were used in the experiements and had not been exposed to ectoparasiticides having a monthly efficacy or shorter 3 months prior to treatment, and were never exposed to long lasting ectoparasiticides (Experiment A (Exp. A): 6 males and 4 females, 10.7 to 11.4 months of age, weighing 6.9-9.2 kg; Experiment B (Exp. B): 8 males and 8 females, 14.1 to 14.9 months of age, weighing $8.1-10.4 \mathrm{~kg}$ ). The dogs were housed individually in stainless steel cages with an exercise area, under controlled environmental conditions, fed with a commercial dry dog food ration, with water available ad libitum. No concurrent medication was given during the study. They were managed similarly and with due regard 
for their well-being. Animals were handled in compliance with Merial Animal Care and Use Guidelines and in compliance with the French regulatory requirements and ethical committee of Toulouse Veterinary School. The dogs were acclimated to the study conditions for at least 11 days prior to treatment and were observed for general health conditions throughout the study.

\section{Sandfly exposures}

Sandfly exposures were performed one week prior to treatment for allocation purposes, and after treatment on Days 1, 7, 14, 21 and 29. Prior to each exposure, animals were anesthetized with intra-muscular injections of 0.02 to $0.03 \mathrm{mg} / \mathrm{kg}$ dexmedetomidine (Dextomidor ${ }^{\ominus}$, Pfizer), 3.8 to $6.8 \mathrm{mg} / \mathrm{kg}$ ketamine (Imalgene ${ }^{\oplus} 1000$, Merial) and 0.46 to $0.65 \mathrm{mg} / \mathrm{kg}$ of Diazepam (Valium ${ }^{\oplus}$, Roche); placed individually into a sandfly proof exposure cage; and exposed to $80 \mathrm{P}$. perniciosus unfed female sandflies (strain originated from Lisbon, Portugal and maintained under laboratory conditions for 9 years). After approximately $60 \mathrm{~min}$, live sandflies were removed from the exposure cage, counted and categorized as engorged (fed) or nonengorged (unfed). Dead sandflies remaining in the exposure cage or on the dog were counted and categorized as engorged or non-engorged. The dogs were then returned to their normal housing. Live sandflies recovered from each exposure (except pre-treatment) were maintained at appropriate environmental conditions for approximately $4 \mathrm{~h}$ after the exposure period ended, and dead phlebotomes were recovered and counted from each container.

\section{Allocation and treatment}

To allocate the dogs, blocks were formed, based on descending pre-treatment counts of fed sandflies and 26 dogs were randomly allocated to the two treatment groups (10 for Exp. A and 16 for Exp. B). Dogs in Group 1 served as untreated control dogs. Dogs in Group 2 were treated on Day 0 with the topical combination of permethrin and fipronil. In Exp. A, 5 dogs were treated at the minimum recommended dose $(0.1 \mathrm{~mL} / \mathrm{kg}$ based on Day 0 body weight, corresponding to a dose of $6.73 \mathrm{mg} / \mathrm{kg}$ fipronil and $50.16 \mathrm{mg} / \mathrm{kg}$ permethrin) whereas in Exp. B, 8 dogs were treated at the recommended commercial dose $(1.0 \mathrm{~mL}$ for dogs $<10.0 \mathrm{~kg}$, and $2.0 \mathrm{~mL}$ for $\operatorname{dogs}>10.0$ to $20 \mathrm{~kg}$, based on Day 0 body weight, delivering a minimum dose of $6.76 \mathrm{mg} / \mathrm{kg}$ fipronil and $50.48 \mathrm{mg} / \mathrm{kg}$ permethrin).

The dose was applied by parting the hair and applying the formulation directly onto the skin on the dorsal midline of the neck. The total volume was divided into two approximately equal portions. One fraction was applied between the base of the skull and the shoulder blades and the other fraction was applied at the front of the shoulder blades. The dogs were observed prior to treatment and hourly for $4 \mathrm{~h}$ following treatment administration.

\section{Data analysis}

\section{Percent sandfly repellency}

The total number of engorged (alive + dead) sandflies at the end of each post-treatment exposure period was transformed to the natural logarithm of (count +1$)$ for calculation of geometric means (GM) by treatment group. Percent repellency was expressed as the percent reduction in fed sandflies of the treated group compared to the control group at each post-treatment exposure day: $100 \times[(\mathrm{C}-\mathrm{T}) / \mathrm{C}]$, where $\mathrm{C}$ is the $\mathrm{GM}$ of the control group and $\mathrm{T}$ is the GM of the treated group.

\section{Percent insecticidal efficacy}

All sandflies were collected at $60 \mathrm{~min}$ after exposure and classified as dead or alive. The live sandflies were put in containers and observed at $4 \mathrm{~h}$ post-exposure. The number of live sandflies after each post-treatment exposure was calculated by subtracting the number of dead sandflies at $4 \mathrm{~h}$ and the number of dead sandflies observed at the end of the $60 \mathrm{~min}$ exposure. The number of live sandflies was transformed to the natural logarithm of (count +1$)$ for calculation of geometric means. Percent insecticidal efficacy at $4 \mathrm{~h}$ post-exposure was calculated as $100 \times[(\mathrm{C}-\mathrm{T}) / \mathrm{C}]$, where $\mathrm{C}$ is the mean of live sandflies in the control group and $\mathrm{T}$ is the mean in the treated group.

The treated group was compared to the control group using Friedman's rank test with blocks defined as the allocation blocks. The testing was two-sided and used a significance level of $5 \%$.

\section{Results}

No health abnormalities related to treatment were observed throughout the studies, including during hourly observations conducted for $4 \mathrm{~h}$ immediately after treatment.

In Exp. B, Dog 6277 in the control group vomited on Day 0 and then was normal through Day 7. The dog did not eat well from Days 8 to 14 and was not considered to be suitable for anesthesia and subsequent exposure to sandflies on Day 14. An intussusception was observed at ultrasonography on Day 15 and the dog was removed from the study, therefore the control group of Exp. B moved from 8 to 7 dogs on Days 14, 21 and 29.

Untreated control dogs had high numbers of engorged sandflies at the end of the exposure period at all timepoints with means between 54.6 and 68.2 out of 80 (Table 1). With at least $68 \%$ of feeding behaviour on control dogs, it showed a robust sandfly strain population. The survival rate was also very good with at least $73.1 \%$ sandflies surviving until $4 \mathrm{~h}$ after the end of the exposure times in the control group (Table 2). 
Table 1 Percent repellency of Phlebotomus perniciosus in dogs treated with the combination of fipronil and permethrin (Experiments A \& B) based on geometric means

\begin{tabular}{|c|c|c|c|c|c|c|}
\hline \multirow{3}{*}{$\frac{\text { Exposure day experiment }(\mathrm{A} / \mathrm{B})}{1(\mathrm{~A})}$} & \multicolumn{4}{|c|}{ Number of engorged sandflies } & \multirow{2}{*}{\multicolumn{2}{|c|}{ Repellency (\%) }} \\
\hline & \multirow{2}{*}{$\begin{array}{l}\text { Dogs (n) } \\
5\end{array}$} & \multirow{2}{*}{$\begin{array}{l}\text { Untreated dogs } \\
60.0\end{array}$} & \multirow{2}{*}{$\begin{array}{l}\text { Dogs (n) } \\
5\end{array}$} & \multirow{2}{*}{$\begin{array}{l}\text { Treated dogs } \\
3.4\end{array}$} & & \\
\hline & & & & & $94.4^{*}$ & $98.2 \% *$ \\
\hline $1(\mathrm{~B})$ & 8 & 64.4 & 8 & 0.4 & $99.4^{*}$ & \\
\hline $7(A)$ & 5 & 60.5 & 5 & 3.2 & $94.7^{*}$ & $98.5 \% *$ \\
\hline 7 (B) & 8 & 61.3 & 8 & 0.2 & $99.7^{*}$ & \\
\hline $14(\mathrm{~A})$ & 5 & 59.3 & 5 & 0.4 & $99.3^{*}$ & $99.2 \% *$ \\
\hline 14 (B) & 7 & 63.1 & 8 & 0.6 & $99.1^{*}$ & \\
\hline $21(\mathrm{~A})$ & 5 & 54.8 & 5 & 7.3 & $86.6^{*}$ & $90.9 \% *$ \\
\hline $21(B)$ & 7 & 64.7 & 8 & 4.6 & $92.9^{*}$ & \\
\hline $29(\mathrm{~A})$ & 5 & 54.6 & 5 & 1.5 & $97.3^{*}$ & $90.3 \% *$ \\
\hline $29(B)$ & 7 & 68.2 & 8 & 12.6 & $81.5^{*}$ & \\
\hline
\end{tabular}

*Significant difference between the population means of the treated and control groups $(p<0.05)$.

Right column gives the \% repellency based on geometric means obtained for each dog, pooling the two experiments, it is not the simple mean of the two \% of repellency calculated for each experiment.

\section{Repellency}

Treated dogs had significantly fewer fed sandflies at the end of the exposure period than untreated control dogs for all study days (Exp. A, p =0.025, Exp. B, $\mathrm{p} \leq 0.008$ ). The percent sandfly repellency after $60 \mathrm{~min}$ exposure was 98.2, 98.5, 99.2, 90.9 and 90.3\% (Table 1), for Days $1,7,14,21$, and 29 , respectively.

\section{Insecticidal efficacy}

Treated dogs had significantly more dead sandflies at $4 \mathrm{~h}$ post-exposure than untreated control dogs for all challenge days (Exp. A, p =0.025, Exp. B, $\mathrm{p} \leq 0.008$ ).

Percent insecticidal efficacy of the treated group at $4 \mathrm{~h}$ compared to the control group on Days 1, 7, 14, 21 and 29 was 98.7, 99.7, 96.8, 93.4, and 78.9\% (Table 2), respectively. In Exp. A, the insecticidal efficacy was $54.9 \%$ on Day 21 and got back to $90.6 \%$ on Day 29.

\section{Discussion}

The number of female sandflies used for each exposure was limited to 80 instead of a more classical number of 100 females $[8,9]$ because of the large number of dogs in each study (10 dogs in Exp. A and 16 dogs in Exp. B) and the difficulty of rearing large numbers of female sandflies under laboratory conditions. There was no impact on the outcome of the studies due to the high rates of feeding and viability in the control groups.

The feeding behaviour of the sandflies on control dogs showed a robust population on all exposures days with at least $68 \%$ having fed after $60 \mathrm{~min}$ in the control group.

Table 2 Percent insecticidal efficacy against Phlebotomus perniciosus observed at $4 \mathrm{~h}$ in dogs treated with the combination of fipronil and permethrin (Experiments A \& B) based on Geometric means

\begin{tabular}{|c|c|c|c|c|c|c|}
\hline \multirow[b]{2}{*}{ Exposure day experiment (A/B) } & \multicolumn{4}{|c|}{ Number of live sandflies } & \multirow[b]{2}{*}{ Efficacy (\%) } & \\
\hline & Dogs (n) & Untreated dogs & Dogs (n) & Treated dogs & & \\
\hline $1(\mathrm{~A})$ & 5 & 74.3 & 5 & 0.3 & $99.6^{*}$ & $98.7 \% *$ \\
\hline $1(\mathrm{~B})$ & 8 & 73.5 & 8 & 1.6 & $97.9^{*}$ & \\
\hline $7(A)$ & 5 & 75.2 & 5 & 0 & $100^{*}$ & $99.7 \% *$ \\
\hline $7(B)$ & 8 & 72.1 & 8 & 0.4 & $99.5^{*}$ & \\
\hline $14(A)$ & 5 & 74.5 & 5 & 5.7 & $92.3^{*}$ & $96.8 \% *$ \\
\hline $14(B)$ & 7 & 72.1 & 8 & 1.2 & $98.4^{*}$ & \\
\hline $21(A)$ & 5 & 75.2 & 5 & 33.9 & $54.9^{*}$ & $93.4 \%$ * \\
\hline $21(B)$ & 7 & 74.0 & 8 & 1.0 & $98.7^{*}$ & \\
\hline $29(A)$ & 5 & 74.2 & 5 & 7.0 & $90.6^{*}$ & $78.9 \%$ * \\
\hline $29(B)$ & 7 & 75.1 & 8 & 25.7 & $65.7^{*}$ & \\
\hline
\end{tabular}

*Significant difference between the population means of the treated and control groups $(p<0.05)$.

Right column gives the \% insecticidal activity based on geometric means obtained for each dog, pooling the two experiments, it is not the simple mean of the two $\%$ of insecticidal activity calculated for each experiment. 
Sandfly survival was also very good with at least $73.1 \%$ surviving until $4 \mathrm{~h}$ after the end of the exposure times in the control group.

The potential for a topical product to provide protection against sandfly-transmitted diseases depends on its ability to prevent the sandflies from taking a blood meal. Hence, the prevention of sandfly feeding was the major focus of this study. The new combination product showed a high repellency rate over one month with a plateau lasting until 21 days post-treatment $(\geq 99.2 \%)$ and a progressive decrease to $90.3 \%$ on Day 29 . A repellency over $80 \%$ is considered as a minimum threshold by the registration agencies and other authors $[8,9]$. This level of efficacy was also observed in other similar studies testing topical combinations including permethrin. Miro et al. [10] evaluated the activity of imidacloprid + permethrin (Advantix ${ }^{\circ}$ ) against $P$. perniciosus and reported $\geq 96.45 \%$ until Day 14 , 92.73\% on Day 21 and $74.7 \%$ on Day 28. Lienard et al. [11] assessed the repellent efficacy of another topical combination of dinotefuran + permethrin + pyriproxyfen (Vectra 3D), under the same experimental conditions, in the same location, and with the same Phlebotomus strain as in the present investigation. The repellency was $96.9,99.7,98.7,83.5$ and $87.0 \%$ on days $1,7,14,21$ and 28 , respectively. The mortality effect was $97.8,99.8$, $73.7,27.5$ and $39.6 \%$ on days $1,7,14,21$ and 28 , respectively. Against P. papatasi, Mencke et al. [12] found Advantix ${ }^{\circ}$ efficacy to be $\geq 93.3 \%$ until Day 8 , then 80.0, 72.8 and $55.9 \%$ on Days 15, 22 and 29, respectively. Molina et al. [13] tested a topical combination of permethrin alone (Exspot ${ }^{\circ}$ ) against P. perniciosus and reported efficacy $\geq 93.4 \%$ until Day 8 then $86.8,67.6$ and $61.0 \%$ on Days 15, 22 and 29, respectively. The observed results for the new topical combination of fipronil and permethrin are clearly close to what has been already published with other spot on formulation containing permethrin.

Insecticidal efficacy, as a secondary parameter, was high until Day 21 (93.4\%), decreasing to $78.9 \%$ on Day 29. The insecticidal effect can be attributed to the action of both fipronil and permethrin, whereas the repellent activity of the product is likely due to the permethrin. Even if not a direct comparison, the mortality effect looks higher with the fipronil-permethrin combination than with the dinotefuran-permethrin-pyriproxyfen $[7,11]$, under the same experimental conditions in the same laboratory and with the same sandfly strain.

In Exp. A, the insecticidal activity dropped on Day 21 to $54.9 \%$ and was $90.6 \%$ on Day 29 , whereas it was 98.7\% on Day 21 in Exp. B and then 65.7\% on Day 29. The regular decrease was as expected in Exp. B. The lower insecticidal activity observed in treated dogs in Exp. A on Day 21 is difficult to explain as no particular variation was observed for the repellent effect, and no variation in the controls. It shows how it is important to include enough dogs in a study: 5 dogs is too limited and the 8 dogs included in Exp. B were important to compensate these observations. We could argue that the number of dogs is probably not sufficient and that a repetition of studies, using the same design, could confirm observations. This is certainly why the registration agencies request at least 2 efficacy studies (called dose confirmations) to confirm an indication $[8,9]$.

\section{Conclusions}

The new combination of fipronil and permethrin demonstrated a significant repellent effect against $P$. perniciosus bites as soon as it was applied on the dogs, and its repellent efficacy lasted 4 weeks. The results suggest that in endemic areas, the regular application of the new combination could be integrated in a canine leishmaniosis prevention program.

\section{Competing interests}

Merial S.A.S. funded this study. The authors are either employees or contractors of Merial.

Frontect ${ }^{\oplus}$ is a registered trademark of Merial in France and pending registration in other countries. All other trademarks are the property of their respective owners. Frontect ${ }^{\oplus}$ is also named Frontline Tri-Act ${ }^{\oplus}$.

This document is provided for scientific purposes only. Any reference to a brand or trademark herein is for informational purposes only and is not intended for a commercial purpose or to dilute the rights of the respective owner(s) of the brand(s) or trademark(s).

\section{Authors' contributions}

$\mathrm{PD}, \mathrm{BF}, \mathrm{EB}, \mathrm{FB}$ and $\mathrm{MF}$ participated in the design of the study and protocols. $E B, E L, P J$ and MF carried out the studies. EB compiled and analysed the data. PD was responsible for the first draft of the manuscript which was then substantially revised by all authors. All authors read and approved the final manuscript.

\section{Acknowledgements}

The authors are sincerely grateful to Martine Roques, Sonia Gounaud and Solange Vermot who took part in the study and ensured adherence to GCP standards.

\section{Author details}

${ }^{1}$ Merial S.A.S., 29 Av Tony Garnier, 69007 Lyon, France. ${ }^{2}$ Institut National Polytechnique (INP) - Ecole Nationale Vétérinaire de Toulouse, 23 Chemin des Capelles, 31076 Toulouse, France.

Received: 20 January 2015 Accepted: 21 January 2015

Published online: 27 January 2015

\section{References}

1. Alexander B, Maroli M. Control of phlebotomine sandflies. Med VeEntomol. 2003;17:1-18.

2. Beugnet F, Marié JL. Emerging arthropod-borne diseases of companion animals in Europe. Vet Parasitol. 2009;163:298-305.

3. Beugnet F, Chalvet-Monfray K. Impact of climate change in the epidemiology of vector-borne diseases in domestic carnivores. Comp Immunol Microbiol Infect Dis. 2013;36:559-66.

4. Otranto D, Dantas-Torres F. The prevention of canine leishmaniasis and its impact on public health. Trends Parasitol. 2013;29:339-45.

5. Davoust B, Roqueplo C, Parzy D, Watier-Grillot S, Marié JL. A twenty-year follow-up of canine leishmaniosis in three military kennels in southeastern France. Parasit Vectors. 2013;6(1):323.

6. Beugnet F, Franc $M$. Insecticide and acaricide molecules and/or combinations to prevent pet infestation by ectoparasites. Trends Parasitol. 2012;28:267-79. 
7. Mercier $P$, Jasmin $P$, Sanquer A. Prevention of sandfly attack by topical application of a permethrin/pyriproxyfen combination on dogs. Vet Ther. 2003;:4:309-16.

8. EMEA. 2000. VICH Topic GL9 (GCP). Guideline on Good Clinical Practices. The European Agency for the Evaluation of Medicinal Products (EMWA CVMPNICH/595/98-Final). http://www.ema.europa.eu/docs/en_GB/ document_library/Scientific_guideline/2009/10/WC500004343.pdf)

9. Marchiondo AA, Holdsworth PA, Fourie LJ, Rugg D, Kellmann K, Snyder DE, et al. World Association for the Advancement of Veterinary Parasitology (W.A.A.V.P.) second edition: guidelines for evaluating the efficacy of parasiticides for the treatment, prevention and control of flea and tick infestations on dogs and cats. Vet Parasitol. 2013;194:84-97.

10. Miro G, Galvez R, Mateo M, Montoya A, Descalzo MA, Molina R. Evaluation of the efficacy of a topically administered combination of imidacloprid and permethrin against Phlebotomus perniciosus in dog. Vet Parasitol. 2007;143:375-9.

11. Lienard E, Bouhsira E, Jacquiet P, Warin S, Kaltsatos V, Franc M. Efficacy of dinotefuran, permethrin and pyriproxyfen combination spot-on on dogs against Phlebotomus perniciosus and Ctenocephalides canis. Parasitol Res. 2013;112:3799-805.

12. Mencke N, Volf P, Volfova V, Stanneck D. Repellent efficacy of a combination containing imidacloprid and permethrin against sandflies (Phlebotomus papatasi) in dogs. Parasitol Res. 2003;90 Suppl 3:S108-11.

13. Molina R, Espinosa-Gongora C, Galvez R, Montoya A, Descalzo MA, Jimenez $\mathrm{Ml}$, et al. Efficacy of $65 \%$ permethrin applied to dogs as a spot-on against Phlebotomus perniciosus. Vet Parasitol. 2012;187:529-33.

\section{Submit your next manuscript to BioMed Central and take full advantage of:}

- Convenient online submission

- Thorough peer review

- No space constraints or color figure charges

- Immediate publication on acceptance

- Inclusion in PubMed, CAS, Scopus and Google Scholar

- Research which is freely available for redistribution 